\title{
Acute Electrocorticography (EcoG) During Mesial Temporal Lobe Epilepsy Surgery-Review
}

\author{
Sajeesh Parameswaran* and Anu Mohan \\ Department of Neurosciences, Ananthapuri Hospitals and Research Institute, India
}

Submission: January 19, 2018; Published: May 24, 2018

*Corresponding author: Sajeesh Parameswaran, M.Sc DNT, Electroencephalographer (Certified by Asian Epilepsy Academy (ASEPA), ASEAN Neurological Association (ASNA) and Indian Epilepsy Society (IES) Department of Neuroscience, Ananthapuri Hospitals and Research Institute, Trivandrum, Kerala, India, 695024, Email: psajeesh@gmail.com

\begin{abstract}
Temporal lobe epilepsy is the commonest type of partial epilepsy and surgery for intractable temporal lobe epilepsy is the most common form of epilepsy surgery performed world over, with consistently goods results. Mesial temporal lobe epilepsy (MTLE) constitutes around 80$90 \%$ of all temporal lobe epilepsies. The surgical procedures commonly carried out for MTLE include standard anterior temporal lobectomy with amygdalohippocampectomy (ATL+AH), electrocorticographically guided tailored resections of the amygdale, hippocampus and the neocortical structures, and selective amygdalohippocampectomy. The role of intra-operative acute electrocorticography (ECoG) during temporal lobe surgery remains controversial despite being in use for over 6 decades.
\end{abstract}

Keywords: ECoG; Temporal lobe epilepsy; Anterior temporal lobectomy

Abbreviations: MTLE: Mesial Temporal Lobe Epilepsy; TLE: Temporal Lobe Epilepsy; MTLE: Mesial Temporal Lobe Epilepsy; MTS: Mesial Temporal Sclerosis; ATL+AH: Anterior Temporal Lobectomy with Amygdalohippocampectomy; STG: Superior Temporal Gyrus; ITG: Inferior Temporal Gyrus; ST: Sub Temporal; MTG: Middle Temporal Gyrus

\section{Introduction}

Temporal lobe epilepsy (TLE) is the commonest type of partial epilepsy, and surgery for intractable TLE is the most common form of epilepsy surgery performed world over, with consistently good results [1,2]. Mesial temporal lobe epilepsy (MTLE) constitutes around $80-90 \%$ of all temporal lobe epilepsies, while lateral temporal neocortical epilepsy accounts for the remaining $10-20 \%$ [3]. The commonest pathological substrate

for MTLE is mesial temporal sclerosis (MTS) [4]. The surgical procedures commonly carried out for MTLE include standard anterior temporal lobectomy with amygdalohippocampectomy $(\mathrm{ATL}+\mathrm{AH})$, electrocorticographically guided tailored resections of the amygdala, hippocampus and the neocortical structures (tailored resection) and selective amygdalohippocampectomy (Figure 1-3).

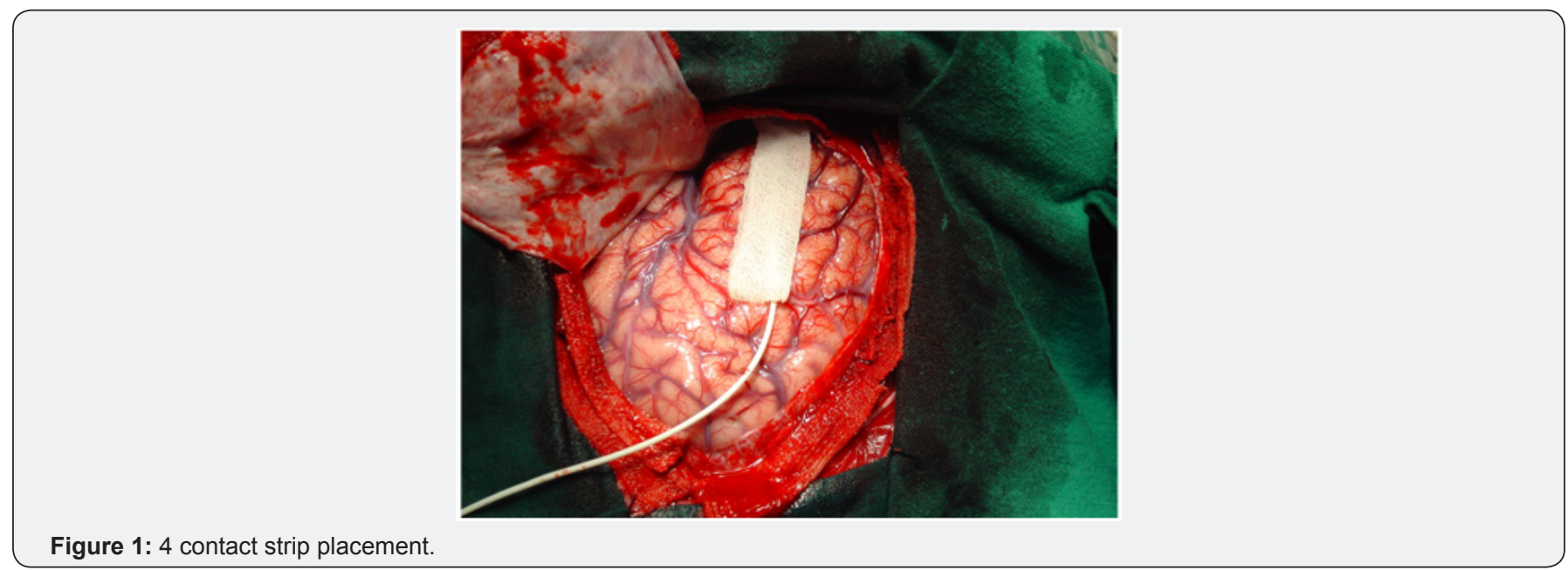




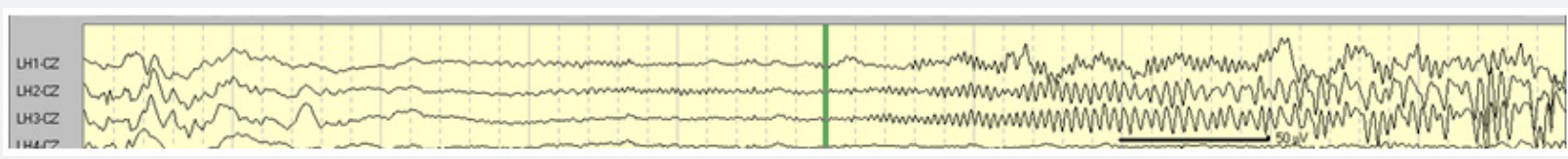

Figure 2: High amplitude inter ictal epileptiform discharges in ECoG.

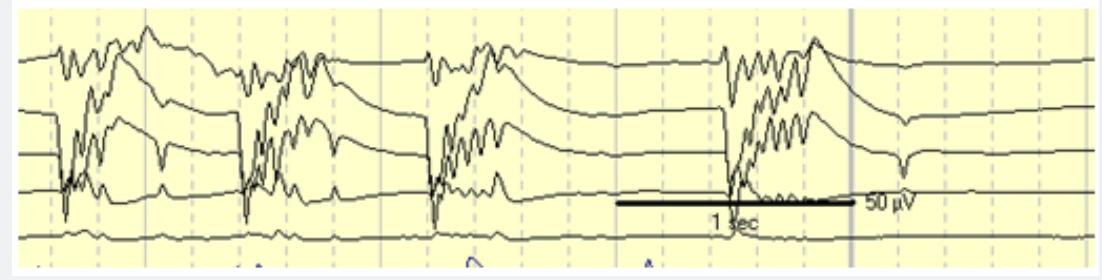

Figure 3: High amplitude ECoG spikes.

The role of intra-operative acute electrocorticography (ECoG) during temporal lobe surgery remains controversial despite being in use for over 6 decades. While some centers perform ECoG routinely, others do not depend on ECoG results. In a survey in 1993 among 42 epilepsy centers world over, 19\% centers never performed ECoG during surgery for MTLE [5]. Several questions need answers: do all spiking regions need to be resected? What is the significance of continued spiking posterior to the resection margin? While many studies have shown that it is important to remove as much of the spiking regions as possible without producing neurological deficits for good seizure outcome [6-10], others do not agree with this concept [11-14]. Several authors have shown that ECoG can guide the amount of mesial temporal and lateral neocortical tissue to be resected, thereby preventing unnecessary removal of uninvolved tissue, with good results, the so-called tailored resections $[15,16]$.

\section{Acute ECoG in ATL+AH}

Usually patients undergo standard anterior temporal lobectomy and amygdalo-hippocampectomy (ATL+AH) for intractable mesial temporal lobe epilepsy. Few patients only undergo tailored resection or selective amygdalohippocampectomy. Acute ECoG usually records after discontinuing isoflurane anesthesia. Simultaneous recording of all the temporal neo-cortical and mesial structures are recommended. However; the following the recording strategy can also be done.

A 4-contact electrode strip then sequentially places on the superior temporal gyrus (STG), inferior temporal gyrus (ITG) and sub temporal region (ST). For the STG and ITG, contact 1 of the strip becomes anterior and contact 4 turn out to be posterior (Figure 1). For sub temporal region, contacts 1 and 2 lay close to the para hippocampus gyrus and contacts 3 and 4 lay laterally, on the under surface of the ITG. Through the middle temporal gyrus (MTG), a 4-contact depth electrode inserts with the presumed head of hippocampus, contacts 1 and
2 presumably inside the heads of hippocampus and contacts 3 and 4 within the MTG. For each position, 3 minutes of recording recommended. After neocortical temporal resection, which consisted of maximum $4 \mathrm{~cm}$ on the left side and $5 \mathrm{~cm}$ on the right side, amygdala and hippocampus were exposed. Two contacts of the $4 \mathrm{~cm}$ depth electrode then inserts sequentially into the amygdala, head, body and tail of the hippocampus. Recording for at least 2 minutes at each site. However, many centers doing simultaneous recording from the mesial and lateral structures. After resection of these mesial structures, post resection ECoG recording for 3 minutes, by placing the 4 contact strip over the resection margin with contact 4 overlying the ITG and contact 1 over the STG. Epileptiform abnormalities consist of spikes, sharp waves, rhythmic spikes and electrographic seizure patterns (Figure 2 \& 3). The polarity is mostly negative but amygdale and hippocampus spikes frequently have a positive polarity of varying amplitudes. At each site, the spikes and number spikes/ minute can be calculated to determine the maximal spiking zone for each patient $[17,18]$.

\section{Does Acute Ecog Helpful?}

The maximal spiking zone in the mesial temporal structures in the majority of the patients with amygdale being the most frequently spiking zone followed by the head and the body of the hippocampus when compare to lateral neo-cortex. This pattern of involvement was found in many studies [19-21].

Alarcon et al. [20] have shown the most common pattern of spiking is from the mesial to lateral sub temporal neo-cortex. Spikes seen in the lateral neo-cortex in the mesial group probably represents propagation from mesial structures and removal of the mesial structures would result in significant reduction or abolition of neocortical spikes. Utrero et al. [22] studied the pathophysiological relationship between mesial and lateral neocortical spikes in 33 patients with nonlesional TLE and demonstrated that the commonest pattern was spikes located only in the mesial temporal structures, followed by mesial spikes propagated to lateral neo-cortex. 


\section{Open Access Journal of Neurology \& Neurosurgery}

Gomez Utero et al. [22], who also shown that when preresection spiking was confined to the mesial structures, patients had god postoperative outcome, while those with predominantly lateral temporal neocortical spiking had a poorer outcome. McBride et al. [23] found that persistence of more than 50\% spikes at the end of the resection resulted a poor outcome. However, other studies have not found a correlation between residual spiking and seizure outcome. Tran et al carried out standard ATL+AH in 47 patients regardless of the ECoG findings and found no correlation between residual spiking and the seizure freedom [24]. Similarly, Chatrian et al. [21], also found no correlation between residual spiking and the seizure freedom among 72 patients, who underwent tailored resection.

These conflicting results may be related to the manner in which ECoG data are analyzed. Alarcon et al. [20] demonstrated leading regions within the mesial as well as the anterior temporal and sub temporal structures by performing online analysis using a computer program. Removal of the leading regions resulted good outcome whereas non removal resulted poor outcome. Therefore, it appears that identification and the removal of all leading regions is more important than the removal of all spikes. Many studies reveal that spikes in acute ECoG are not helpful for identifying the borders of epileptogenic anterior temporal resection [25]. However, the importance and practice of intra operative ECoG is considered as a useful tool [26]. Most common cause of surgical failure in TLE is thought to be insufficient hippocampal resection $[27,28]$. Intra operative hippocampal ECoG can predict how much hippocampus should be resected to achieve maximal seizure-free outcome, thus allowing to spare the functionally important hippocampus [29]. The Relationship between the extent of resection of mesial structures and postsurgical seizure outcome have been well studied by different centers [30-33]. Newer studies published regarding prognostic significance of inter ictal spikes and highfrequency oscillations in ECoG and MRI-guided laser-interstitial have been published $[34,35]$. Luther $\mathrm{N}$ et al. have correlated acute intraoperative ECoG findings with ictal onset zone in chronic ECoG recording in patients with magnetic resonance imaging (MRI) normal TLE. They found that acute ECoG in MRInegative TLE may helpful to categorize a subset of patients who could proceed straightforwardly to standard anteromesial resection without undergoing chronic invasive recording [36].

\section{Conclusion}

The usefulness of acute ECoG during standardized mesial temporal lobe epilepsy surgery is limited. However, acute ECoG may be helpful in tailored temporal lobectomy; especially to identify the extent of epileptogenic area. Post resection residual spikes on ECoG may associate with a poor seizure control.

\section{References}

1. Radhakrishnan K (1999) Medically refractory epilepsy. In: Radhakrishnan K (Ed.), Medically refractory epilepsy. Sree Chitra Tirunal Institute for Medical Sciences and Technology, India.
2. Engel J (1996) Surgery for seizures. N Engl J Med 334(10): 647-652.

3. Theodore WH (2004) Distinguishing lateral temporal neocortical and mesial temporal lobe epilepsy. Epilepsy Curr 4(2): 55-56.

4. Radhakrishnan VV, Rao MB, Radhakrishnan K, Thomas SV, Nayak DS, et al. (1999) Pathology of temporal lobe epilepsy: An analysis of 100 consecutive specimens from patients with medically refractory epilepsy. Neurol India 47(3): 196-201.

5. Engel J (1993) Surgical Treatment of the Epilepsies. Raven Press, New York, USA.

6. Jasper HH, Pertuisset B, Flanigen H (1951) EEG and cortical electrocorticograms in patients with temporal lobe seizures. Arch Neurol Psychiatry 65: 272-299.

7. Penfield W, Jasper HH (1954) Epilepsy and the functional anatomy of the human brain. Little, Brown, Boston, UK.

8. Rasmussen $T$ (1975) Cortical resection in the treatment of focal epilepsy. In: Purpura DP, Penry JK, Walter RD (Eds.), Neurosurgical management of the epilepsies, Raven Press, New York, USA.

9. Graf M, Niedermeyer E, Schiemann J, Uematsu S, Long DM (1984) Electrocorticography: Information derived from intraoperative recordings during seizure surgery. Clin Electroencephalogr 15(2): 8391.

10. Jennum, Dhuna A, Davies K, Fiol M, Maxwell R (1993) Outcome of resective surgery for intractable partial epilepsy guided by subdural electrode arrays. Acta Neurol Scand 87(6): 434-437.

11. Falconer MA (1958) Discussion: In: Baldwin M, Bailey P (Eds.), Temporal Lobe Epilepsy. Thomas, Springfield, USA.

12. Engel J (1987) Approaches to localization of the epileptogenic lesion. In: Engel (Ed.), Surgical Treatment of the Epilepsies. Raven Press, New York, USA.

13. Spencer DD, Isneri J (1992) Temporal lobectomy. In: Luders HO (Ed.), Epilepsy Surgery. Raven Press, New York, USA.

14. Tran TA, Spencer SS, Javidan M, Pacia S, Marks D, et al. (1997) Significance of spikes recorded on intraoperative electrocorticography in patients with brain tumor and epilepsy. Epilepsia 38(10): 11321139.

15. McKhann GM, Schoenfeld-McNeill J, Born DE, Haglund MM, Ojemann GA (2000) Intraoperative hippocampal electrocorticography to predict the extent of hippocampal resection in temporal lobe epilepsy surgery. J Neurosurg 93(1): 44-52.

16. Kanner AM, Kaydanova Y, deToledo-Morrell L, Morrell F, Smith MC, etal (1995) Tailored anterior temporal lobectomy. Relation between extent of resection of mesial structures and postsurgical seizureoutcome. Arch Neurol 52(2): 173-178.

17. Chatrian GE, Quesney LF (1998) Intraoperative Electrocorticography. In: Engel J, Pedley TA (Eds.), Epilepsy-A Comprehensive Textbook, Lippincott-Raven, New York, USA.

18. Yang T, Hakimian S, Schwartz TH (2014) Intraoperative Electro Cortico Graphy (EcoG): indications, techniques, and utility in epilepsy surgery. Epileptic Disorders 16(3): 271-279.

19. Kanazawa O, Blume WT, Girvin JP (1996) Significance of spikes at temporal lobe electrocorticography. Epilepsia 37(1): 50-55.

20. Alarcon G, Garcia Seoane JJ, Binnie CD, Martin Miguel MC, Juler J, et al. (1997) Origin and propagation of interictal discharges in the acute electrocorticogram. Implications for pathophysiology and surgical treatment of temporal lobe epilepsy. Brain 120(12): 2259-2282.

21. Chatrian GE, Tsai ML, Temkin NR, Holmes MD, Pauri F, et al. (1998) Role of the ECoG in tailored temporal lobe resection: the University of Washington experience. Electroencephalogr Clin Neurophysiol 48: 24-43. 


\section{Open Access Journal of Neurology \& Neurosurgery}

22. Gomez Utero E, Sanchez Alonso A Alijarde MT, Navarrete EG (2001) Prognostic value of electrocorticography in temporal lobe epilepsy: patterns of relationing mesial and neocortical activity. Rev Neurol 33(9): 801-808.

23. McBride MC, Binnie CD, Janota I, Polkey CE (1991) Predictive value of intraoperative electrocorticograms in resective epilepsy surgery. Ann Neurol 30(4): 526-532.

24. Tran TA, Spencer SS, Marks D, Javidan M, Pacia S, et al. (1995) Significance of spikes recorded on electrocorticography in nonlesional medial temporal lobe epilepsy. Ann neurol 38(5): 763-770.

25. Falconer MA, Hill D, Myer A, Mitchell W, Pond DA (1955) Treatment of temporal lobe epilepsy by temporal lobectomy: a survey of findings and results. Lancet 268(6869): 827-835.

26. Engel J (1997) Comment on the predictive value of intraoperative electrocorticography in resections for limbic epilepsy associated with mesial temporal sclerosis. Neurosurgery 40(2): 310-311.

27. Polkey C, Awad I, Tanaka T (1993) The place of reoperation. In: Surgical reatment of Epilepsies. Raven Press, New York, USA, pp. 663-667.

28. Germano IM, Poulin N, Olivier A (1994) Reoperation for recurrent temporal lobe epilepsy. J Neurosurg 81(1): 31-36.

29. McKhann GM, Schoenfeld-McNeill J, Born DE, Haglund MM, Ojemann GA (2000) Intraoperative hippocampal electrocorticography to predict the extent of hippocampal resection in temporal lobe epilepsy surgery. J Neurosurg 93(1): 44-52.
30. Nayel MH, Awad IA, Luders H (1991) Extent of mesiobasal resection determines outcome after temporal lobectomy for intractable complex partial seizures. Neurosurgery 29(1): 55-61.

31. Jooma R, Yeh HS, Privitera MD. Rigrish D, Gartner M (1995) Seizure control and extent of mesial temporal resection. Acta Neurochirurgica 133(1): 44-49.

32. Stefan H, Pauli E, Eberhard F, Ugrinovich R, Buchfelder M (1996) "Tailoring" resections in drug refractory temporal lobe surgery (German). Der Nervenarzt 67(4): 306-310.

33. da Silva AB, Ferrari-Marinho T, Caboclo LO, Yacubian EM, Queiroz CM (2014) 019-(DAS0163) Prognostic significance of interictal spikes and high-frequency oscillations in ECoG acutely recorded during temporal lobe epilepsy surgery. Epilepsy\& Behavior 38: 189.

34. Luedke MW, Pietak MR, Serafini S, Haglund MM, Sinha SR (2016) Intraoperative ECoG during MRI-guided laser-interstitial therma therapy for intractable epilepsy. J Clin Neurophysiol 33(4): e28-e30.

35. Luedke MW, Pietak MR, Serafini S, Haglund MM, Sinha SR (2016) Intraoperative ECoG during MRI-guided laser-interstitial thermal therapy for intractable epilepsy. J Clin Neurophysiol 33(4): e28-e30.

36. Luther N, Rubens E, Sethi N, Kandula P, Labar DR, et al. (2011) The value of intraoperative electrocorticography in surgical decision making for temporal lobe epilepsy with normal MRI. Epilepsia 52(5): 941-948.

\section{Your next submission with Juniper Publishers} will reach you the below assets

- Quality Editorial service

- Swift Peer Review

- Reprints availability

- E-prints Service

- Manuscript Podcast for convenient understanding

- Global attainment for your research

- Manuscript accessibility in different formats

( Pdf, E-pub, Full Text, Audio)

- Unceasing customer service

Track the below URL for one-step submission https://juniperpublishers.com/online-submission.php 